\title{
Apresentação - Literatura Gênero epistolar: a carta na literatura, a literatura na carta, rede de sociabilidade, escrita de si ...
}

Regina Kohlrausch ${ }^{1}$

Programa de Pós-Graduação em Letras, Faculdade de Letras da Pontifícia Universidade Católica do Rio Grande do Sul.

reginakohlrausch@pucrs.br
- ste número da Revista Letrônica dedica-se ao gênero epistolar em seu sentido amplo, abrindo para o estudo da carta na literatura ou a literatura na carta, tendo como motivação e objetivo contribuir com a pesquisa epistolográfica tratada em revistas como Teresa, em 2008, e Letras de Hoje, 2014, cada uma na sua especificidade. A chamada deste número convidava, por isso, à reflexão sobre a presença da carta na literatura ou a carta como documento informativo/expressivo acerca do processo de criação literária, das redes de sociabilidade intelectual e artística, do exercício de crítica literária ou ainda da expressão de matéria autobiográfica, a "escrita de si".

A carta, segundo Foucault (2006, p. 149-159), "é algo mais do que um adestramento de si próprio pela escrita, por intermédio dos conselhos e opiniões que se dão ao outro", porque "ela constitui também uma certa maneira de cada um se manifestar a si próprio e aos outros". Afirma ainda que ela, a carta, "faz o escritor "presente" àquele a quem a dirige", porque escrever é "mostrar-se, dar-se a ver, fazer aparecer o rosto próprio junto ao outro", ela é, por isso, "simultaneamente um olhar que se volta para o destinatário e uma maneira de o remetente se oferecer ao seu olhar pelo que de si mesmo lhe diz". Por meio dela, "abrimo-nos ao olhar dos outros e instalamos o nosso correspondente no lugar do deus interior". Seguindo tal raciocínio, Foucault explica que o trabalho que a carta opera sobre o destinatário, que também é efetuado sobre o escritor pela própria carta que envia, implica uma "introspecção" entendida como "uma abertura de si que se dá ao outro". Esse tipo de abertura permite, conforme Foucault (2006, p. 152), a "constituição de uma narrativa de si" que é "a narrativa da relação de si" porque se evidenciam dois elementos que vão se tornando objetos privilegiados da relação de si, ou seja, o corpo e os dias. 
Em relação ao corpo, esse é um tema recorrente nas cartas. Ele vai desde a descrição "detalhada das sensações corpóreas, das impressões de mal-estar, das diversas perturbações que se terão podido experimentar", até conselhos que se considera úteis ao correspondente assim como rememorações "de efeitos do corpo sobre a alma" e os respectivos resultados de um sobre o outro e vice-versa ou ainda a reprodução de "movimento que leva de uma impressão subjetiva a um exercício de pensamento". No que se refere ao dia como objeto da narração de si, é possível, pela carta, apresentar-se ao correspondente relatando seu cotidiano, pois faz parte da prática epistolar "dar conta de cada um dos seus dias, hora por hora", passando em revista seu dia, numa espécie de "exame de consciência”, aludido por Sêneca no início da carta 83, destinada a Lucílio (FOUCAULT, 2006, p. 132). Essa narrativa epistolar de si próprio que propicia a coincidência do olhar do outro e daquele que se volve para si próprio serve simultaneamente para um e para o outro, independente do objetivo da carta: "são préstimos recíprocos, quem ensina instrui-se" (FOUCAULT, 2006, p. 147).

Aproveitando esse estudo de Foucault sobre a "Escrita de si", no item “Correspondência”, a partir das cartas de Sêneca para Lucílio, pode-se adentrar no estudo do gênero epistolar contando ainda com o apoio teórico do pesquisador Marcos Antonio de Moraes (2008, p. 8) que recupera a crônica "A quem pertence uma carta" do livro Pour l'autobiographie (1998), Philippe Lejeune, destacando como este último desvela "a complexa natureza das mensagens epistolares: a carta, por definição, é uma partilha. Tem diversas faces: é um objeto (que se troca), um ato (que coloca em cena o 'eu', o 'ele' e os outros), um texto (que se pode publicar...)", explica Moraes (2008, p. 8-9), ressaltando que "cada uma dessas perspectivas (carta/objeto; carta/ato; carta/texto) orbita uma constelação de assuntos, significados e indagações”.

Para Moraes, a carta, vista como objeto cultural, "nos remete ao suporte e a seus significados, assim como à história das condições materiais da troca epistolar, prestando-se também à transfiguração artística, a fetiches e à exploração econômica". Enquanto ato, afirma Moraes (2008, p. 8), "a carta, no campo semântico da representação teatral, coloca "personagens" em "cena", pois o "remetente assume "papéis", ajusta "máscaras" em seu rosto, reinventando-se diante de seus destinatários como objetivos afetivos ou práticos definidos". Enquanto texto, segundo Moraes, validado assim pela retórica e pelos estudos linguísticos/filológicos, a carta/texto

atrai também os olhares das mais diversas áreas do conhecimento, da história à psicologia(e psicanálise), da sociologia e filosofia às artes em geral, das ciências exatas às biológicas, olhares que desejam captar testemunhos e ideologias, fundamentos artísticos e científicos, experiências vividas ou imaginadas. Os estudos culturais privilegiam essa voz da intimidade, atravessada por ideologias. $\mathrm{Na}$ teoria e nos estudos literários, a cara/texto tanto pode ser "material auxiliar", ajudando a compreender melhor a obra e a vida literária, quanto escrita que valoriza a função estética/poética; ou, ainda, "texto literário" nas paragens do romance epistolar (MORAES, 2008, p. 8-9) 
Convém salientar ainda, conforme Moraes (2007, p. 30), que a correspondência de escritores, artistas plásticos, músicos e intelectuais das diversas áreas de conhecimento abre-se para "três perspectivas de estudo". A primeira possibilidade de exploração do gênero epistolar consiste em "recuperar na carta a expressão testemunhal que define um perfil biográfico" porque, segundo Moraes, "confidências e impressões espalhadas pela correspondência de um artista, contam a trajetória de uma vida, delineando uma psicologia singular que ajudam a compreender os meandros da criação literária”. A segunda perspectiva é a que possibilita "apreender a movimentação nos bastidores da vida artística de um determinado período", porque "as estratégias de divulgação de um projeto estético, as dissensões nos grupos e os comentários acerca da produção contemporânea aos diálogos contribuem para que se possa compreender que a cena artística tem raízes profundas nos 'bastidores', onde, muitas vezes, situam-se as linhas de força do movimento", explica Moraes. A terceira possibilidade interpretativa é a que "vê o gênero epistolar como 'arquivo de criação', espaço onde se encontram fixadas a gênese e as diversas etapas de elaboração de uma obra artística, desde o embrião do projeto até o debate sobre a recepção crítica favorecendo a sua eventual reelaboração". Nesse sentido, conclui Moraes, "a carta ocupa o estatuto de crônica da obra de arte".

Retomando a pergunta “A quem pertence uma carta?", formulada por Lejeune, encontra-se reposta, no âmbito brasileiro, em Eliane Vasconcellos (2008, p. 381), quem afirma que a carta pertence ao destinatário, cabendo a ele decidir qual o destino do documento: ler e destruir ou guardar, deixando-as para a posteridade, delegando aos herdeiros a defesa da reputação do morto. Em sua origem, conforme destaca a pesquisadora, a carta é um texto que não deve ser publicado, mas nem sempre se respeita esse estatuto, porque, muitas vezes, é um documento repleto de informações históricas, biográficas, literárias e artísticas.

Para Vasconcellos, as cartas enquadram-se como "documentos expressivos", segundo classificação de Robert C. Angell e Ronald Freedman (1971, p. 294-295), junto com as biografias, os diários e as autobiografias, e que são consideradas os documentos expressivos mais acessíveis, variando de acordo com o ambiente cultural de seus emissores. Como documentos, Vasconcellos (2008, p. 381) alerta sobre a necessidade de compará-las com outras cartas e documentos porque "se deve desconfiar sempre da sinceridade epistolar".

Ao ser publicada, saindo da esfera privada, a carta adquire novo status: "este documento que supostamente diz a verdade, este testemunho da esfera do privado passa a ser olhado por todos e a crítica pode agora opinar sobre as informações que ali aparecem representadas". Porém, alerta Vasconcellos, "autores mudam de opinião ou de pontos de vista e as cartas escritas em determinada época podem ser repudiadas posteriormente" (2008, p. 381).

Considerando seu caráter de "documento expressivo", volta-se o olhar sobre a carta esperando que o seu conteúdo traga informações e/ou novidades acerca do cotidiano e da vida política, de questões socioculturais e literárias, composto 
também pela "escrita de si", com informações pessoais, reflexões e expressões de sentimentos, servindo, na linha de foucaultiana, de coincidência do olhar do outro e daquele que se volve para si próprio simultaneamente para um e para o outro, independente do objetivo da carta, como "préstimos recíprocos, quem ensina instrui-se".

Em relação ao aspecto jurídico, no Brasil, a carta, conforme Lei 6.538, de 1978, é definida como "objeto de correspondência, com ou sem envoltório, sob forma de comunicação escrita, de natureza administrativa, social, comercial, ou qualquer outra, que contenha informação de interesse específico do destinatário"1. Ou seja, a Lei reitera a marca expressiva e também particular devido à informação ou ao conteúdo de interesse o destinatário. Além disso, como explica Vasconcellos (2008, p. 384), as cartas estão protegidas pelo direito de autor, definido por Clóvis Beviláqua como o direito que "tem o autor de obra literária, cientifica, ou artística de ligar o seu nome às produções do seu espírito e de reproduzi-las". Embora o assunto do direito autoral ter merecido certa atenção em 1827, ele adquire sua autonomia jurídica somente com a Lei 5.988/73, alterada em 1998, resultando na Lei 9.610/98, que descreve quais são as obras intelectuais protegidas, e que no artigo 34 faz referências às cartas, dizendo: "Cartas missivas, cuja publicação está condicionada à permissão do autor, poderão ser juntadas como documento de prova em processos administrativos e judiciais"2. Anterior a essa lei, Vasconcellos (2008, p. 385), destaca que a Constituição brasileira de 1988, ao tratar “Dos direitos e garantias fundamentais", no artigo 5oㅡㄹ inciso X, posiciona-se sobre a proteção do direito à intimidade: "São invioláveis a intimidade, a vida privada, a honra e a imagem das pessoas, assegurado o direito à indenização pelo dano material ou moral decorrente de sua violação". Neste sentido, pode-se afirmar que "o signatário detém o direito autoral da carta; o destinatário possui o direito material, ou seja, ele é dono do suporte, normalmente o papel em que a carta foi escrita, e os dois são protegidos pelo direito à intimidade, assim como daqueles que são mencionados no texto em questão" (VASCONCELLOS, 2008, p. 385). Tal situação deve ser levada em conta pelo pesquisador de correspondência, sob pena de cometer crime, conforme definido no artigo 153 do Código Penal brasileiro, pelo fato de "divulgar alguém, sem justa causa, conteúdo de documento particular ou de correspondência confidencial, de que é destinatário ou detentor, e cuja divulgação possa produzir dano a outrem”3. Em função disso, vale incluir ainda a conclusão de Vasconcelos (2008, p. 389), que encerra seu texto reiterando o cuidado necessário daquele que trabalha com cartas porque, se, de um lado, "a sociedade tem o direito à informação", de outro, "o cidadão tem direito à privacidade". 
Validada como documento expressivo, carta, enquanto gênero, é vista à margem da literatura, "uma vez que se produziu longe do intuito primeiro, o literário", no entanto, defende Vasconcellos, as cartas dirigidas a um destinatário real envolvem o aspecto documental e literário, principalmente quando elas são consideradas como parte da obra de um autor, como ocorre nas publicações de obras completas acompanhadas pelas cartas, ou seja, "apesar de não haver na correspondência intenção artística, ela pode ser considerada um gênero literário, isto é, ganha uma pátina estéticaliterária" (VASCONCELLOS, 2008, p. 381-382).

No que se refere ao aspecto gênero epistolar/literatura, a estudiosa de correspondência Walnice Nogueira Galvão, na entrevista concedida à revista Teresa, conduzida por Marcos Moraes, também estudioso do gênero, explica que a partir do texto "Linguística e poética", de Roman Jakobson, "desfrutamos de alguma forma licença para trabalhar com a carta nos estudos Literários" (2008, p. 23). Na mesma entrevista, ao ser questionada sobre a percepção da "carta como "material auxiliar", nunca como texto literário" e se tal fato está vinculado à ausência de um instrumental interpretativo adequado para seu estudo, Galvão responde: “Marcos, é gente como você que está criando o instrumental” (2008, p. 24). Na sequência, Moraes pergunta "se não dá para analisar a carta lançando mão de termos como "foco narrativo", "tipologia de personagens", "espaço", "tempo"...", obtendo como resposta que "as cartas da Madame de Sévigné têm foco narrativo, têm personagens, têm tudo isso (...). Depende da carta, depende do epistológrafo", mas que "nós ainda não temos uma teoria da carta, precisamos acumular mais cartas e acumular mais estudos sobre cartas, para chegar a uma teoria" (2008, p. 24). Na mesma entrevista, Galvão também comenta sobre o limite da carta deixar de ser "documento histórico" e passar a ser "construção literária":

Como saber se a pessoa está inventando? Frequentemente está... Proust inventava à beça nas cartas, queixando-se tanto e de tantas doenças que dá para desconfiar se não seria invenção, uma forma de distanciamento... (...). Algumas cartas são mais documentos do que outras e o difícil está em você equilibrar esses dois pratos da balança, entre o que é documento e o que é invenção. Se há invenção, a invenção pode ser criação artística também. (GALVÃO, 2008, p. 26-27)

Tal situação merece atenção por parte de estudiosos e pesquisadores do gênero epistolar no sentido de oferecer subsídios para essa caracterização enquanto documento histórico, criação artística ou componente da obra de um autor. Se a essência do literário é a ficcionalização da realidade, marcada por um discurso plurissignificativo, sem o compromisso da veracidade dos fatos, e a carta tem o compromisso dessa veracidade, pois ela é um documento expressivo que informa ao outro acerca da vida do emissor, e que é lida, no momento da recepção, como uma verdade, de que forma pode-se dar a ela um caráter de literário? Sabe-se que nem sempre o remetente relata na carta a situação real, omitindo dados ou "fantasiando 
ocorrências" numa tentativa de contar o que gostaria que tivesse acontecido e não o que realmente aconteceu, ou ainda para amenizar determinada situação, buscando evitar que o destinatário sofra ou que fique desgostoso, entristecido, ou, ao contrário, visando ntristece-lo, despertar o desassossego ou a ira do outro. Como é possível definir a presença dessas "verdades inventadas" ou dessas intenções? Sabe-se também que há exemplos de cartas que já confirmaram esse tipo de criação, mas isso não permite generalizar, assim como não é possível considerar o fato de tratar-se de um escritor, pois ali também há a carta comercial, que trata de seus honorários, de seus compromissos editoriais, de seus compromissos públicos, que são reais e, por isso, não podem ser lidos como ficção.

No entanto, se isoladamente o gênero carta exige todo o cuidado, considerando a legislação vigente, e proporciona um debate em relação à especificidade enquanto gênero literário, ao ser incluída numa obra literária, como elemento principal ou secundário, muda-se o foco, pois estamos no campo do romance epistolar como gênero literário, cujo apogeu situase no século XVIII, com destaque para Cartas persas, de Montesquieu; Pâmela, de Samuel Richardson; A nova Heloisa, de Rousseau; Os sofrimentos do jovem Werther, de Goethe; As ligações perigosas, de Choderlos de Laclos, chegando, apenas para citar um romance do século XXI, em Flores azuis, de Carola Saavedra, publicada em 2008. Nesta obra, o leitor se depara com um texto que alterna cartas escritas por " $\mathrm{A}$ ", uma mulher abandonada pelo parceiro, e uma narrativa em terceira pessoa que descreve os efeitos dessa missiva sobre o sujeito protagonista que as lê sem ser o destinatário. São nove cartas, que antecedem a cada um dos nove capítulos, escritas entre os dias 19 e 27 de janeiro, deixadas no endereço do ex-companheiro, num envelope azul, lidas pelo novo morador, também recém-separado, nas quais "A" vai recuperando os pontos altos e baixos da relação que acabou, como se fosse um "inventário de uma separação", que se complementa a cada nova carta, com o objetivo, como se verifica na última carta, de anunciar:

Então, é apenas para isso, esta última carta, e tudo o que te escrevi, apenas para dizer que eu te receberia, se você voltasse, se você quisesse, e se você, sem perceber, estendesse entre nós um atalho, uma ponte. Apenas isso. Eu te receberia sem perguntas, sem exigências, eu beijaria a tua mão e te guiaria até o quarto, o mesmo quarto, o nosso, a mesma cama, lembra? (SAAVEDRA, 2008, p. 151).

Na busca de retomar o tempo da relação, passando em revista a vida em conjunto, numa espécie de escrita de si com vistas a trazer o outro de volta, que a carta exerce sua função de documento expressivo, porque propicia a coincidência do olhar do outro e daquele que se volve para si próprio, servindo simultaneamente para um e outro, conformando, por ser também um elemento constitutivo, o romance de Saavedra como romance epistolar.

Os artigos que compõem este número voltam-se, portanto, para o gênero epistolar, por um lado, olhando para a carta no romance e, por outro, para a carta como documento expressivo que instaura e revela uma rede de sociabilidade 
estabelecida entre sujeitos diversos, que falam de suas produções literárias, de suas concepções de literatura, revelando sua estética e posicionamento sobre as artes. Na perspectiva da carta no romance, mais especificamente, o romance epistolar, Felipe Vale da Silva direciona seu olhar para Pâmela, de Samuel Richardson, para discutir o conceito de virtude e o uso da forma epistolar, objetivando contribuir com os estudos do romance e da importância da literatura no Iluminismo. Nessa mesma perspectiva, mas sem o compromisso da caracterização de romance epistolar stricto sensu, Márcio Miranda Alves enfoca o uso da carta como um elemento importante na estrutura da obra ficcional de Erico Verissimo, mostrando que as cartas, como recurso narrativo, revelam "não apenas o íntimo das personagens, mas introduzem questões históricas e sociais pertinentes para a representação literária”.

Na perspectiva da carta como documento expressivo, Fernando de Moraes Gebra centra sua atenção nas cartas que Fernando Pessoa escreveu entre 1913 a 1916, "período marcado pelas suas crises intelectuais e esotéricas”, cujo estudo permite compreender aspectos simbólicos e metafóricos contidos em poemas transcritos em muitas dessas cartas desse período, graças a manifestação sincera e confessional a seus destinatários. Nessa mesma linha de manifestação, Andréa Correa Paraiso Müller debruça-se sobre o julgamento crítico que Araripe Júnior fez de Flaubert a partir da correspondência do romancista francês publicada no final do século XIX, mais especificamente da carta traduzida e transcrita na coluna “Chronica estrangeira", do Jornal do Commercio, de 16 de dezembro de 1892.

Ainda na perspectiva da carta como documento expressivo, Carolina Sá Teles volta-se para a correspondência de Machado de Assis, mais especificamente à carta pública que o escritor brasileiro escreveu para José Feliciano de Castilhos, no ano de 1865, analisando a comédia Os primeiros amores de Bocage, de José Mendes Leal. Nessa carta, conforme análise da estudiosa, é possível observar "um testemunho da crítica literária produzida pelo autor brasileiro no gênero epistolar", e também "o estabelecimento de relações de sociabilidade e filiação a determinada tradição literária".

Seguindo a caracterização da carta como documento expressivo da escrita de si e também do processo de produção literária de um determinado escritor, André Luiz Alselmi dedica-se ao estudo da correspondência de Caio Fernando Abreu visando "traçar uma visão do escritor gaúcho sobre a função da literatura, a imagem do escritor e o processo de escrita, e demonstrar que as cartas constituem um rico material para a compreensão do universo literário do autor".

Para fechar a edição, levando em conta a discussão sobre a quem pertence uma carta, optou-se pelo texto de Leandro Garcia Rodrigues, que visa, a partir de propostas extraídas de algumas cartas e outros textos teóricos, entender e debater o destino da carta, seu pertencimento - individual ou coletivo? - os problemas legais e morais envolvidos nesta problemática.

Agradecendo aos colaboradores por suas valiosas contribuições, acreditamos ter cumprido com o objetivo de colaborar e divulgar os estudos sobre o gênero epistolar. 


\section{Referências}

BECKER, Colette. “O Discurso da escolta: as notas e seus problemas (o exemplo da correspondência de Zola). In: Revista Patrimônio e Memória. São Paulo, UNESP, v. 9, n.1, jan.-jun. 2013, p. 144-156.

DIAZ, José-Luis. “Qual genética para as correspondências?” Tradução Cláudio Hiro e Maria Sílvia B. Ianni. In: Manuscrítica. Revista de crítica genética, São Paulo, n. 15, 2007.

FOUCAULT, Michel. "A escrita de si". In: . O que é um autor. Lisboa: Vega, 1992, p. 129-160.

GALVÃO, Walnice Nogueira. Desconversa (ensaios críticos). Rio de Janeiro: Editora da UFRJ, 1998.

GALVÃO, Walnice Nogueira; GALOTTI, Oswaldo. Correspondência de Euclides da Cunha. São Paulo: Editora da Universidade de São Paulo, 1997. GALVÃO, Walnice Nogueira; GOTLIB, Nádia Battella (Org.). Prezado senhor, Prezada senhora: estudos sobre cartas. São Paulo: Companhia das Letras, 2000.

GOMES, Ângela de Castro (Org.). Escrita de si, escrita da história. Rio de Janeiro: Editora da FGV, 2004.

LEJEUNE, Philippe. “A quem pertence uma carta?” In: __. . o pacto autobiográfico: de Rousseau à Internet. Org. Jovita M. G. Noronha. Trad. Jovita M. G. Noronha e Maria I. C. Guedes. Belo Horizonte: Editora UFMG, 2008. p. 251-254.

Letras de Hoje. Estudos e debates de assuntos de linguística, literatura e língua portuguesa. Programa de Pós-Graduação em Letras - PUCRS. Porto Alegre, v. 49, n. 2, abr.-jun. 2014.

MALATIAN, Teresa. Cartas. Narrador, registro e arquivo. In: PINSKY, Carla B.; LUCA, Tânia Regina de (Org.). O historiador e suas fontes. São Paulo: Contexto, 2011. p. 195-221.

MORAES, Marcos Antonio de (Org.). Correspondência Mário de Andrade \& Manuel Bandeira. São Paulo: EDUSP, IEB, 2000.

MORAES, Marcos Antonio de. Mário, Otávio: cartas de Mário de Andrade a Otávio Dias Leite (1936-1944). São Paulo: IEB-USP/Imprensa oficial, 2006.

MORAES, Marcos Antonio de. Epistolografia e crítica genética. Ciência e Cultura (SBPC), São Paulo, v. 59, n. 1, p. 30-32, jan.-mar. 2007.

MORAES, Marcos Antonio de Orgulho de jamais aconselhar: a epistolografia de Mário de Andrade. São Paulo: EDUSP/FAPESP, 2007.

PINSKY, Carla B.; LUCA, Tânia Regina de (Org.). O historiador e suas fontes. São Paulo: Contexto, 2011.

ROCHA, João Cezar de Castro. A epistolografia como desafio à História e à Teoria da literatura. In: Exercícios críticos: leituras do contemporâneo. Chapecó: Argos, 2008. p. 145-155.

SÜSSEKIND, Flora; DIAS, Tânia (Org.). A historiografia literária e as técnicas de escrita. Do manuscrito ao hipertexto. Rio de Janeiro: Edições Casa de Rui Barbosa; Vieira e Lent, 2004.

VASCONCELLOS, Eliane. Intimidade das correspondências. In: TERESA Revista de Literatura Brasileira/área de Literatura Brasileira, Departamento de Letras Clássicas e Vernáculas, Faculdade de Filosofia, Letras e Ciências Humanas, Universidade de São Paulo, n. 8/9, p. 372-389, 2008. 